\title{
APPLICATION OF SINGLE-GIMBAL CONTROL MOMENT GYROS FOR ATTITUDE CONTROL OF A RADIO-RANGE EARTH REMOTE SENSING SPACECRAFT
}

\author{
V.N. Platonov ${ }^{1,2}$ \\ A.V. Sumarokov ${ }^{1,2}$ \\ V.S. Ryabikov ${ }^{3}$ \\ S.G. Makeich ${ }^{3}$ \\ L.I. Nekhamkin ${ }^{3}$ \\ V.V. Vilenksiy ${ }^{4}$ \\ S.E. Zaytsev ${ }^{4}$ \\ L.G. Korol ${ }^{4}$ \\ R.O. Rusakov ${ }^{4}$
}

valery.platonov@rsce.ru

anton.sumarokov@rsce.ru

makeichs@yandex.ru

li17@istranet.ru

otd405@vpk.npomash.ru

ZaiSergei@mail.ru

otd405@vpk.npomash.ru

robarusa@gmail.com

${ }^{1}$ S.P. Korolev Rocket and Space Corporation Energia,

Korolev, Moscow Region, Russian Federation

${ }^{2}$ MIPT, Dolgoprudny, Moscow Region, Russian Federation

${ }^{3}$ AO "NIIEM", Istra, Moscow Region, Russian Federation

${ }^{4}$ JSC "MIC "NPO Mashinostroyenia", Reutov, Moscow Region, Russian Federation

\begin{abstract}
The paper presents an outlook into the application of single gimbal control moment gyros as actuators for orientation control of a future radio-range Earth remote sensing (ERS) spacecraft. It describes the precession rate control algorithms for singlegimbal control moment gyros which fulfil the requirements on spacecraft control systems. Mathematical modelling is used in order to show the implementability of the requirements and the assurance of the required stabilization accuracy during the ERS functioning
\end{abstract}

\section{Keywords}

Remote Earth sensing, single gimbal control moment gyros, space gyrodines, angular momentum, stabilization, angular rate, precession

Received 19.07.2018

(C) Author(s), 2019

Introduction. The paper describes a radio-range ERS spacecraft [1]. It is assumed that for the most of its operational life the orientation system of the spacecraft is active controlling its roll (i. e. angle of rotation around its orbit tangent line) $[2,3]$. Figure 1 features the flight scheme and the directions of the coordinate systems fixed on the spacecraft (OXYZ).

It is assumed that the range of roll angles required for ERS functioning is between $-55^{\circ}$ and $+55^{\circ}$. The ability to change the orientation fastly in order to 
Application of Single-Gimbal Control Moment Gyros for Attitude Control...

re-focus the ERS devices on another object is a key capability of an ERS spacecraft. This capability motivates the following requirements: the spacecraft shall be able to make a turn around the roll axis for $110^{\circ}$ in $60 \mathrm{~s}, 35^{\circ}$ in $30 \mathrm{~s}, 25^{\circ}$ in 15 s. During the ERS functioning (radio imaging) the accuracy of the angular rate of the spacecraft shall be within $\pm 0,001 \%$, and the stabilization accuracy within \pm 2 '.

In order to meet the requirements on the roll rate we suggest using single-gimbal control moment gyros (CMG) as roll control system actuators. CMGs allow a significant increase in the manueverability of the spacecraft in comparison to the systems using flywheels. The ability of the

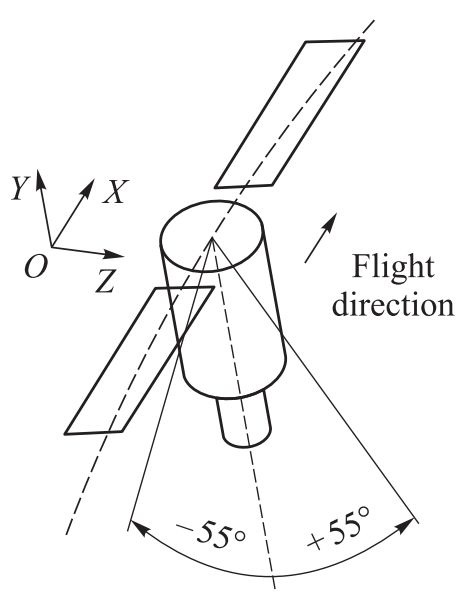

Fig. 1. Spacecraft flight scheme during ERS functioning and $O X Y Z$ axes directions CMGs to create much higher torque than that of the flywheels ensures very low latency in increasing and decreasing the angular rate. The time required for programmed turns is thus greatly reduced.

The kinematic scheme of the CMG system is shown in this paper, alongside the control law required to ensure the needed amount of control torque and to guarantee the requested precession rate. The implementability of the requirements was studied using a mathematical model. The model supports the implementability of the programmed turns according to the requirements stated above.

CMG kinematic scheme. Preliminary estimations of the mass and inertia of the spacecraft yielded the following results:

$$
J=\left[\begin{array}{ccc}
1500 & 0 & 0 \\
0 & 9000 & 0 \\
0 & 0 & 8200
\end{array}\right]
$$

It is assumed that the spacecraft would need rotation mostly around its roll axis (i.e., around the axis where the moment of inertia is minimal). In order to minimize the mass of the system, we suggest using 4 CMGs placed according to $2 \times 2$ scheme. For CMG1 and CMG2 gyrodines, precession axes are parallel to $O Y$ axis of the spacecraft, for CMG3 and CMG4 they are parallel to $O Z$ axis of the spacecraft (Fig. 2). The base for the precession angles of the spacecraft is chosen to be its $O X$ axis. The arrangement described above will result in the highest variation of the angular momentum being around $O X$ axis, i.e., the axis assumed to be the turn axis most frequently. 


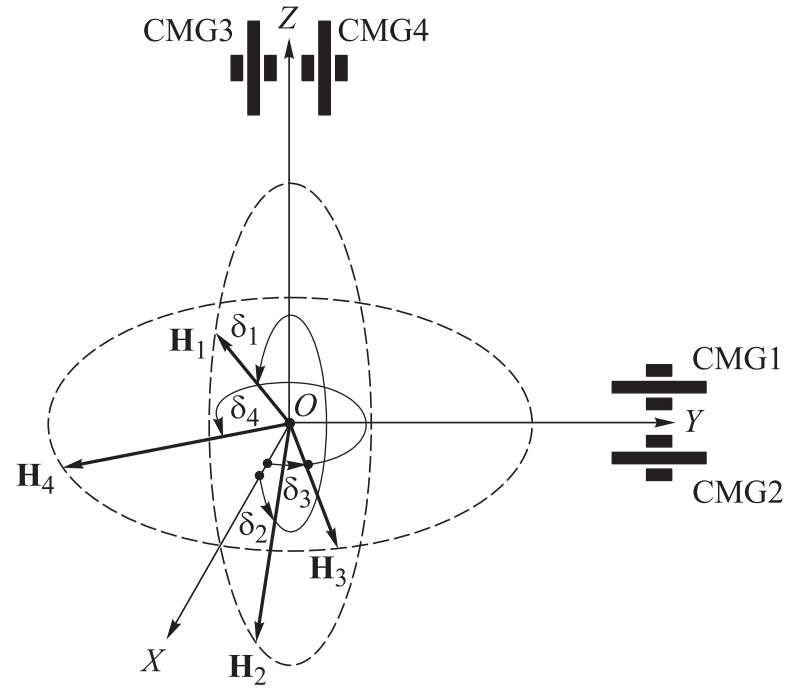

Fig. 2. CMG kinematic scheme

Each CMG shall develop angular momentum of $50 \ldots 60 \mathrm{~N} \cdot \mathrm{ms}$ in order to allow maneuevers around other axes as well. The CMGs with such characteristics are being produced in Russian Federation [4], and they can be used on the spacecraft considered in this paper. All further estimations are provided assuming the angular momentum $h=\left|\mathbf{H}_{i}\right|=50 \mathrm{~N} \cdot \mathrm{ms}(i=1, \ldots, 4)$.

The variations of the angular momentum show distinct differences between the axes: they amount $\pm 200 \mathrm{~N} \cdot \mathrm{ms}$ for $O X$ axis, $\pm 100 \mathrm{~N} \cdot \mathrm{ms}$ for $O Y$ axis, and $\pm 100 \mathrm{~N} \cdot \mathrm{ms}$ for $\mathrm{OZ}$ axis. Therefore, maximum rates for roll, yaw and pitch are $7.5 \%$ s, $0.64 \%$ s, and $0.7 \%$ s respectively.

The total angular momentum for the selected kinematic scheme is defined as follows:

$$
\mathbf{H}=h\left[\begin{array}{c}
\cos \delta_{1}+\cos \delta_{2}+\cos \delta_{3}+\cos \delta_{4} \\
\sin \delta_{3}+\sin \delta_{4} \\
-\sin \delta_{1}-\sin \delta_{2}
\end{array}\right]
$$

Here $\delta_{1}, \delta_{2}, \delta_{3}, \delta_{4}$ are gimbal angles for CMG1, CMG2, CMG3 and CMG4.

Denoting the actuator control torque for each CMG as $\boldsymbol{m}_{\boldsymbol{i}}$, we define the following Jacobian matrix for the system of gyros:

$$
\begin{aligned}
\mathbf{m}_{i} & =\left(\partial \mathbf{H}_{i} / \partial \delta_{i}\right) / h ; \\
\mathbf{D}\left(\mathbf{m}_{1}, \mathbf{m}_{2}, \mathbf{m}_{3}, \mathbf{m}_{4}\right) & =\left[\begin{array}{cccc}
-\sin \delta_{1} & -\sin \delta_{2} & -\sin \delta_{3} & -\sin \delta_{4} \\
0 & 0 & \cos \delta_{3} & \cos \delta_{4} \\
-\cos \delta_{1} & -\cos \delta_{2} & 0 & 0
\end{array}\right] .
\end{aligned}
$$


Application of Single-Gimbal Control Moment Gyros for Attitude Control...

Actuator torque control law. The method for control law definition here is similar to those used in Ref. [5-7].

The maneuever (rotation) is performed around a finite rotation vector. The time required for the maneuever shall be minimized. Assume that the misalignment angles are given by the following quaternion:

$$
\mathbf{N}=\mathbf{N}\left(v_{0}, v_{x}, v_{y}, v_{z}\right)=\left[\cos \Theta \sin (\Theta) e_{x} \sin (\Theta) e_{y} \sin (\Theta) e_{z}\right]^{t},
$$

where $\Theta$ is required angle of rotation around the finite rotation vector; $e_{i}, i=x, y, z$, are components of the unitary vector of the rotation axis.

The required control torque of the CMGs is calculated via maximal acceleration $a$, which the system can provide in the direction of the final rotation vector. The acceleration is in turn calculated based on the information of the spacecraft's moments of inertia and the range of the control torque currently available (1). The require control torque of the gyro system is defined using the following formula:

$$
M_{t i}=-J_{i} k_{1 i}\left(\omega_{F i}-\omega_{B i}-\omega_{r} e_{i}\right)+(\omega \times \mathbf{G})_{i}, i=x, y, z .
$$

Here, $k_{1 i}$ are amplification coefficients for angular rate; $\omega_{F i}$ are spacecraft's angular rate components, calculated using dynamic filtering; $\omega_{B i}$ are components of the target angular rate level for the current orientation task; $\omega_{r}=a_{1} t$ is calculated rate around the final rotation vector, $t=0$ time of the initiation of the maneuver, $a_{1}=0,75 a ; J_{x}, J_{y}, J_{z}$ are moments of inertia of the spacecraft around $O X, O Y, O Z$ axes respectively; $(\omega \times \boldsymbol{G})_{i}$ are projection of the cross product $\boldsymbol{\omega} \times \mathbf{G}$ on $O X, O Y$, and $O Z$ axes, $\mathbf{G}=\mathbf{J} \boldsymbol{\omega}+\mathbf{H}$ is total angular momentum vector of the gyro system $(\mathbf{H})$ and the spacecraft.

The increase of $\omega_{r}$ in (3) is halted when the total angular momentum of the gyro system $\mathbf{H}$ reaches $90 \%$ of its maximal value for the given direction, or when the maximum angular rate is achieved.

When the maneuver is finished, braking is performed with the acceleration of $a_{1}$. Braking initiation time is chosen according to $\omega_{r}>\sqrt{2 a_{1}|\Theta|}$ condition. The angular rate during the braking phase decreases proportionally to the value of $a_{1}$. Assuming the misalignment is small, i.e., the condition $\sqrt{2 a_{1 i}\left|\Theta_{i}\right|} \geq \Theta_{i}\left(k_{2 i} / k_{1 i}\right)$, with $\Theta_{i}$ being the misalignment in the corresponding channel, and $a_{1 i}$ being the projection of the acceleration in the direction of the corresponding channel, holds, the control law for the torque has the following form for each channel: 


$$
M_{t i}=-J_{i}\left(k_{2 i} 2 v_{i}+k_{1 i}\left(\omega_{F i}-\omega_{B i}\right)\right)+(\omega \times \mathbf{G})_{i}, i=x, y, z .
$$

Here, $k_{2 i}$ are amplification coefficients for angular misalignments.

Equation of precession rates for CMGs. The control law is defined based on the precession rates $\dot{\delta}_{i}(i=1, \ldots, 4)$ providing the required control torque $\mathbf{M}_{t}$ [8] defined according to (3) and (4):

$$
-\dot{\mathbf{H}}=\mathbf{M}_{c}-\omega \times \mathbf{H}=\mathbf{M}_{t} .
$$

Here the input torque $\mathbf{M}_{c}$ is defined as $\mathbf{M}_{c}=-h \mathbf{D} \dot{\delta}$, where $h=\left|\mathbf{H}_{i}\right|$ is the amount of the angular momentum for each CMG, $\dot{\delta}\left(\dot{\delta}_{1}, \dot{\delta}_{2}, \dot{\delta}_{3}, \dot{\delta}_{4}\right)$ is the gyrodine's precession vector. Defining $\mathbf{M}_{c}^{\star}=\mathbf{M}_{t}+\boldsymbol{\omega} \times \mathbf{H}$, for (5) we get

$$
-h \mathbf{D} \dot{\delta}=\mathbf{M}_{t}^{*} \text {. }
$$

The system discussed in this paper uses 4 CMGs and therefore it is redundant regarding the control task it is implementing. The following function will be minimized to generate the optimal control law:

$$
\Phi=-\left(\mathbf{m}_{1} \times \mathbf{m}_{2}\right)^{2}-\left(\mathbf{m}_{3} \times \mathbf{m}_{4}\right)^{2} .
$$

The minimization of (7) is required for redistribution the total angular momentum of the system between single gyros in order to avoid the system realizing the special points [7]. Subscripts in (7) are defined in the same way as on Fig. 2. The precession rates are defined using the function of the following form:

$$
I=\dot{\delta}^{t} \dot{\delta}+\rho \mathbf{f}^{t} \dot{\delta}
$$

The function (8) is subject to conditions (6) and (7). The component $\rho(\delta) \geq 0$ represents weighting function, measured in angular rate units. The components of the $n$-dimensional vector $f$ are

$$
f_{i}=\frac{\partial \Phi}{\partial \delta_{i}}, i=1, \ldots, 4
$$

The minimization of (8) under conditions (6) and (7) can be solved using Lagrange multipliers method. The Lagrange function $F$ is

$$
F=I+\lambda^{t}\left(\mathbf{D} \dot{\delta}+\mathbf{M}_{t}^{*} / h\right),
$$

where $\lambda=\lambda\left(\lambda_{1} \lambda_{2} \lambda_{3}\right), \lambda_{1}, \lambda_{2}, \lambda_{3}$ are Lagrange multipliers. Taking the derivative of $F$ upon $\dot{\delta}$ and $\lambda$, yields 7 equations with 7 unknowns

$$
2 \dot{\delta}+\rho \mathbf{f}+\mathbf{D}^{t} \lambda=0
$$




$$
\mathbf{D} \dot{\delta}=-\mathbf{M}_{t}^{\star} / h
$$

Based on (11) and (12), the Lagrange multipliers are defined by the following equations:

$$
\lambda=\left(\mathbf{D D}^{t}\right)^{-1}\left(2 \mathbf{M}_{t}^{\star} / h-\rho \mathbf{D f}\right) .
$$

Substituting (13) into (11), the control law for CMG system is the following:

$$
\dot{\delta}=-\mathbf{D}^{t}\left(\mathbf{D} \mathbf{D}^{t}\right)^{-1} \frac{\mathbf{M}_{t}^{*}}{h}+\frac{1}{2} \rho\left(\mathbf{D}^{t}\left(\mathbf{D D}^{t}\right)^{-1} \mathbf{D}-\mathbf{E}\right) \mathbf{f},
$$

where $\mathbf{E}$ is unitary matrix. Gramm matrix $\mathbf{D} \mathbf{D}^{t}$ for (14) is calculated via (2).

It is worth mentioning that the control law defined by (14) should be amended in a way that excludes the possibility of the matrix $\left(\mathbf{D D}^{t}\right)^{-1}$ to become singular. The precession rates $\dot{\delta}$ shall be limited, as described in Ref. [5, 8].

The control law acc. to (14) has CMGs control torque maximized. For the spacecraft under consideration, it can be assumed that for the whole range of orientation angles, the control torque is always maintained above $25 \mathrm{~N} \cdot \mathrm{ms}$ in any direction.

Spacecraft control system functioning mathematical simulation. The simulation is parametrized according to the requirements from the spacecraft control system. Amplification coefficients for angular rate and angle are selected using the theory of control optimization [9]: $k_{1 i}=1.92$ and $k_{2 i}=1.44$ $(i=x, y, z)$. The weight function has the form of $\rho=2 / d^{2}$, where $d=\left|\mathbf{D D}^{t}\right|$.

The components of angular rate of the spacecraft $\omega_{F i}(i=x, y, z)$ are obtained using dynamic filtration algorithms [10-13]. The bandwidth of the filter is $6 \mathrm{rad} / \mathrm{s}$. The elasticity of the spacecraft's body was not considered for modelling; however, gravity-related forces as well as specific characteristics of the angular rate sensors and the implemented CMGs were considered. On-board software was used in the loop of the model. Timestep used for the modelling amounted $0.2 \mathrm{~s}$. The software in the loop included the actual protocols for information exchange between the on-board computers and the CMGs. The prescanning orientation procedure was modelled as described in Ref. [14].

The range for CMGs' precession rates was chosen to be $0.0069 . . .57 .3 \%$. We assumed that any precession rate can be requested, from the lower boundary of the range till the upper boundary, with the step being equal to the lower boundary. The required accuracy was limited to $\pm(1 \%+0.0069 \%)$. The model considered the disturbance torques induced by the CMGs' rotor drivers. The transfer function of the CMGs' drivers was similar to the one described in Ref. [15]. 
V.N. Platonov, A.V. Sumarokov, V.S. Ryabikov, S.G. Makeich
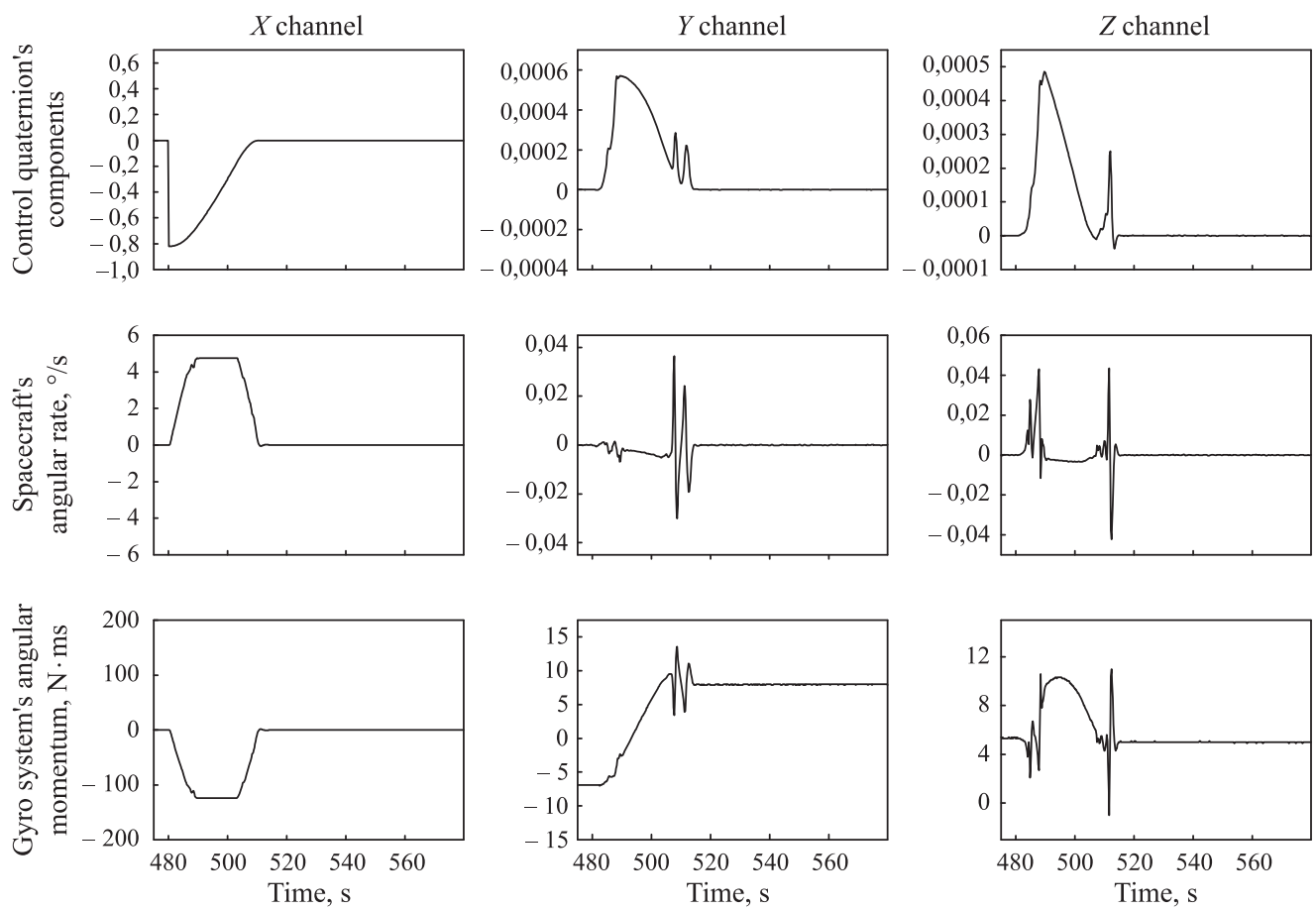

$a$
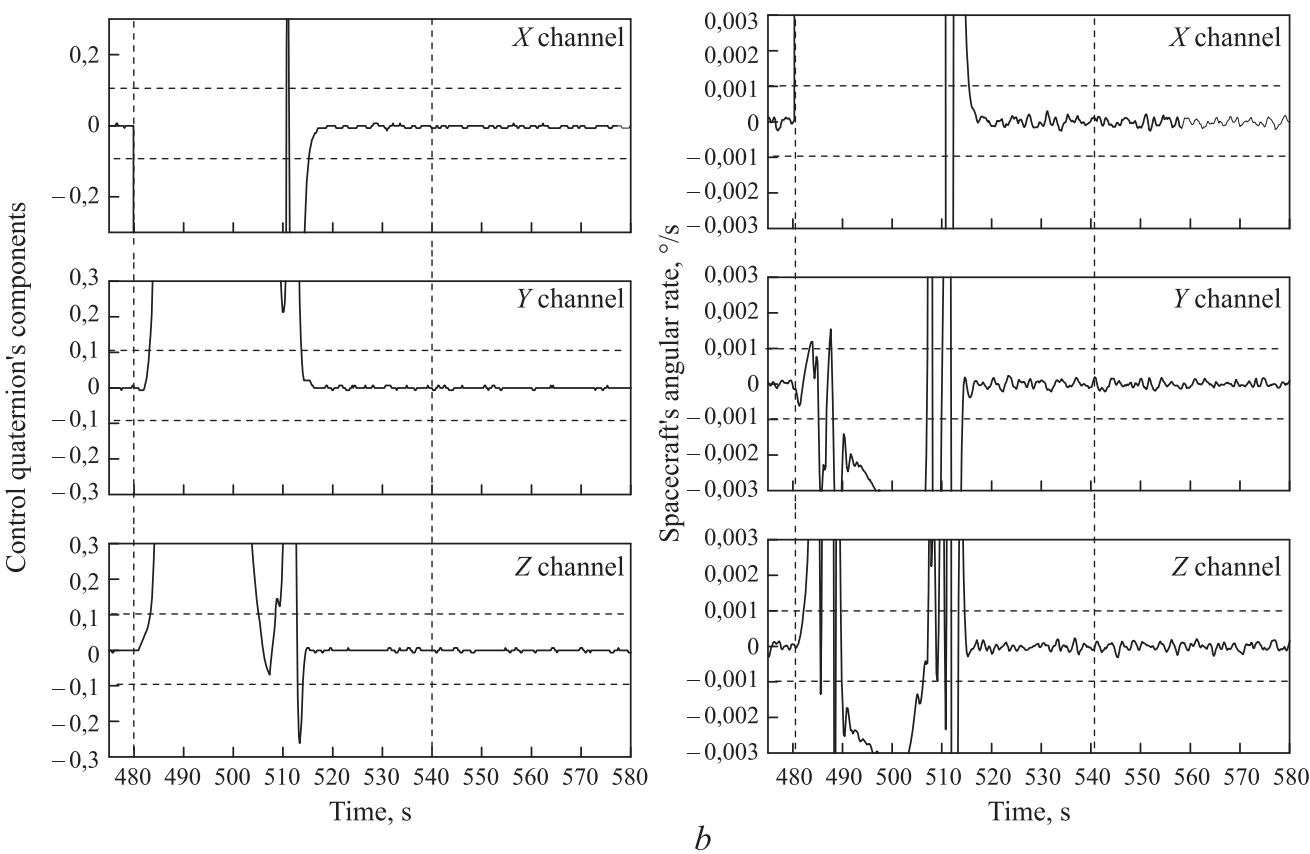

Fig. 3. Parameters of the spacecraft's rotation over the angle of $110^{\circ}(a)$, repeated on a larger scale $(b)$ 
Application of Single-Gimbal Control Moment Gyros for Attitude Control...

Roll turns spanning the angles of $110^{\circ}, 35^{\circ}$ and $25^{\circ}$ (before vertical dash line) with subsequent steady state of $45 \mathrm{~s}$ (after vertical dash line) were modelled in order to validate the requirements from the spacecraft's orientation system. During the turn, dynamic characteristics of the model were assessed, while during the steady state the main assessed factor was the accuracy of the stabilization over time.

Figure 3 shows the results of the modelling of the $110^{\circ}$ roll turn. Figure $3 a$ includes the change of control quaternion's components, spacecraft's angular rate and the gyro system angular momentum. Figure $3 b$ repeats the data on the control quaternion's components, showing them on a larger scale. The data provided support the requirement for $110^{\circ}$ turn being implemented in less than $60 \mathrm{~s}$ (it actually took nearly $40 \mathrm{~s}$ to turn the spacecraft for $110^{\circ}$ ) as well the post-maneuever accuracy requirements.

Figure 4 shows the results of the modelling of the $35^{\circ}$ roll turn. Figure $4 a$ includes the change of control quaternion's components, spacecraft's angular rate and the gyro system angular momentum. Figure $4 b$ repeats the data on the control quaternion's components, showing them on a larger scale. The data provided support the requirement for $35^{\circ}$ turn being implemented in less than $30 \mathrm{~s}$ (it actually took nearly $23 \mathrm{~s}$ to turn the spacecraft for $110^{\circ}$ ) as well the post-maneuever accuracy requirements.


Fig. 4 (part 1). Parameters of the spacecraft's rotation over the angle of $35^{\circ}(a)$ 
V.N. Platonov, A.V. Sumarokov, V.S. Ryabikov, S.G. Makeich
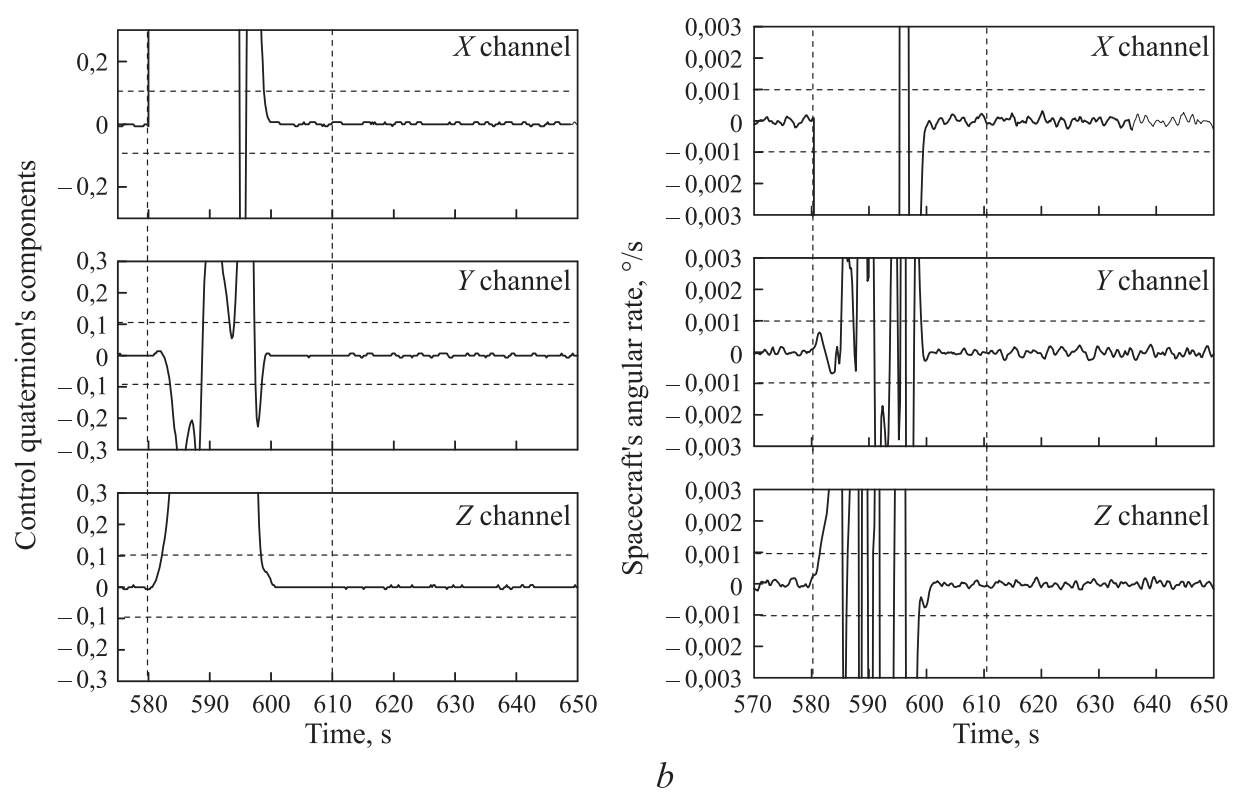

Fig. 4 (part 2). Parameters of the spacecraft's rotation repeated on a larger scale (b)

Figure 5 shows the results of the modelling of the $25^{\circ}$ roll turn. Figure $5 a$ includes the change of control quaternion's components, spacecraft's angular rate and the gyro system angular momentum. Figure $5 b$ repeats the data on the control quaternion's components, showing them on a larger scale. The data provided support the requirement for $25^{\circ}$ turn being implemented in less than $15 \mathrm{~s}$ as well the post-maneuever accuracy requirements.
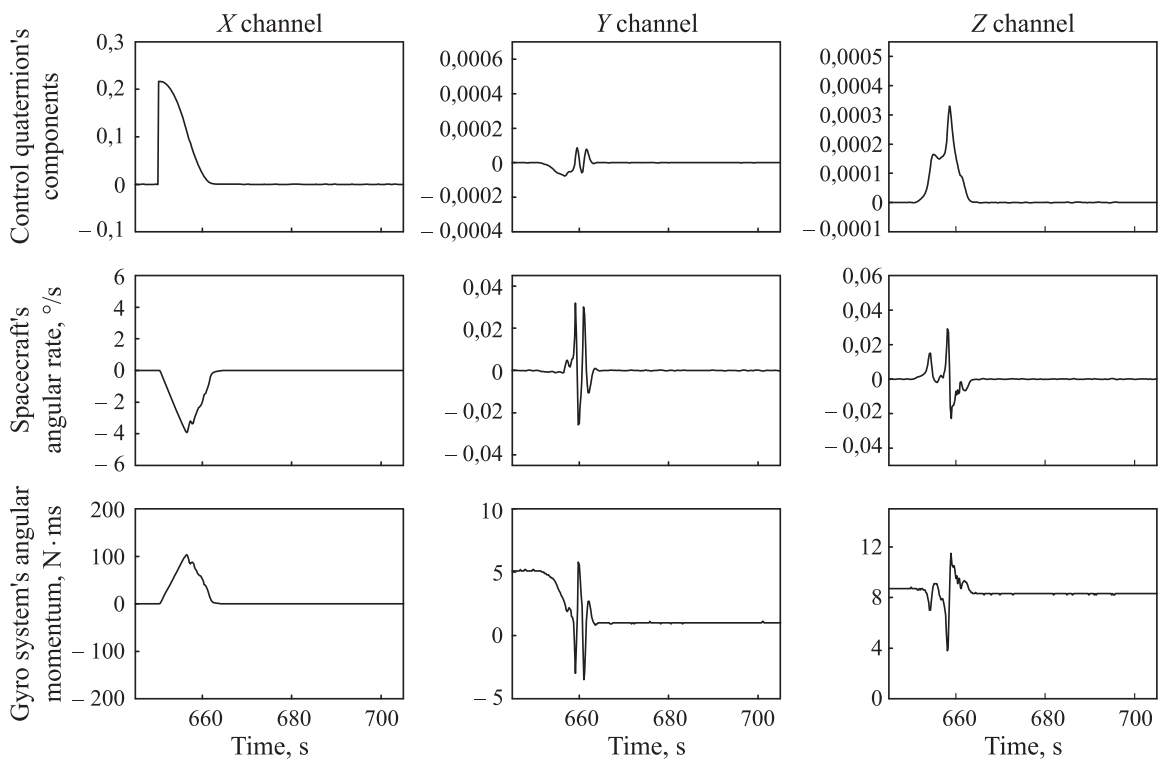

Fig. 5 (part 1). Parameters of the spacecraft's rotation over the angle of $25^{\circ}(a)$ 
Application of Single-Gimbal Control Moment Gyros for Attitude Control...
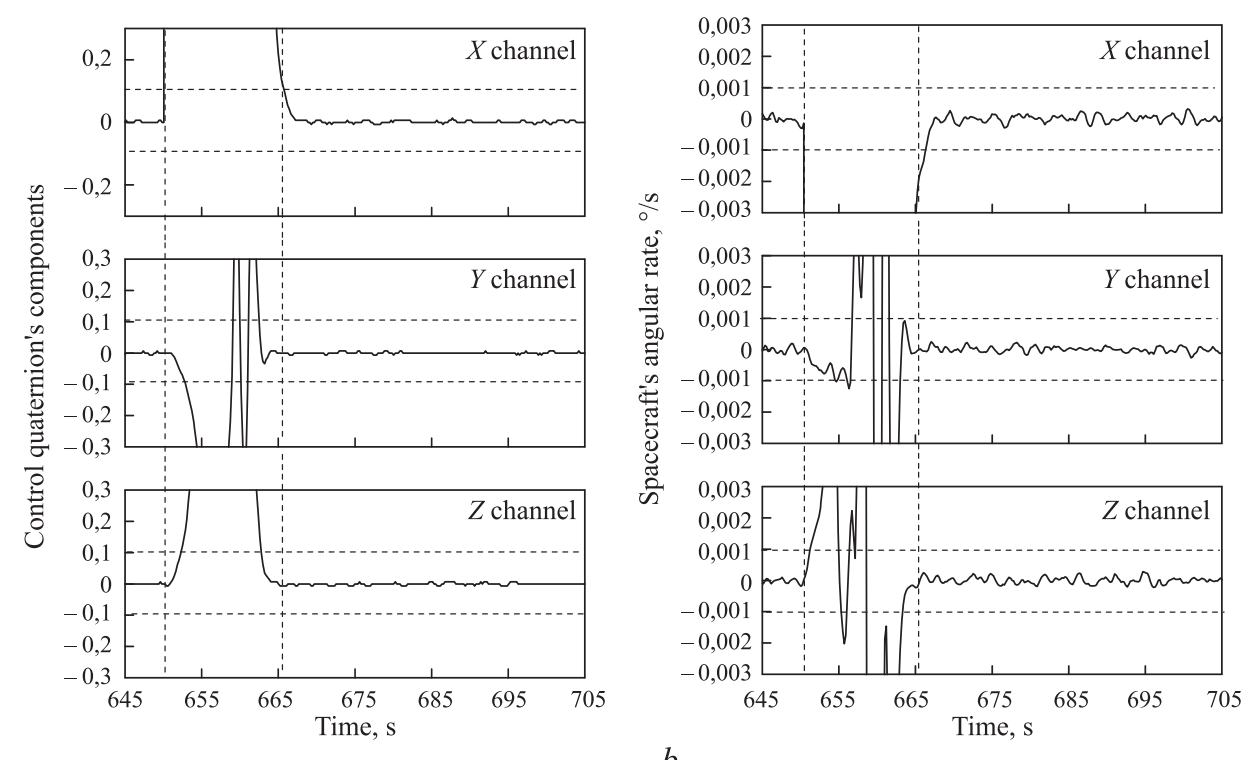

$b$

Fig. 5 (part 2). Parameters of the spacecraft's rotation repeated on a larger scale (b)

Conclusion. This paper provides an overview of the scanning mode used by an innovative Earth remote sensing spacecraft. Single-gimbal CMGs are used as actuators in this spacecraft's orientation system. The scope of the paper includes selection of the kinematic scheme as well as design of the control laws for spacecraft's orientation and CMGs' precession rates. Parameters selected for the control laws support implementation of the requirements on the spacecraft's control system. The investigation performed on the model of the target system has demonstrated that those requirements were met.

Translated by O. Kirovskii

\section{REFERENCES}

[1] Shikhanov S.V., Ovchin K.D. [Analysis of the state and trend of development of the modern orbital group of remote sensing of the Earth]. III Vseros. nauch.-praktich. konf. "Sovremennyye problemy sozdaniya i ekspluatatsii vooruzheniya, voyennoy i spetsial'noy tekhniki" [III All-Russian Sci.-Pract. Conf. "Modern problems of creation and operation of weapons, military and special equipment"]. St. Petersburg, Mozhaysky Military Space Academy, 2016, pp. 279-283 (in Russ.).

[2] Borisenko N.Yu., Sumarokov A.V. On the rapid orbital attitude control of manned and cargo spacecraft Soyuz MS and Progress MS. J. Comput. Syst. Sci. Int., 2017, vol. 56, iss. 5, pp. 886-895. DOI: 10.1134/S1064230717050033

[3] Sumarokov A.V., Timakov S.N. On an adaptive control system for angular motion of a communication satellite. J. Comput. Syst. Sci. Int., 2008, vol. 47, iss. 5, pp. 795-805. DOI: 10.1134/S1064230708050134 
V.N. Platonov, A.V. Sumarokov, V.S. Ryabikov, S.G. Makeich

[4] Mkrtychyan A.R., Bashkeev N.I., Akashev D.I., et al. [Developments of AO "NII komandnykh priborov" for spacecraft motion control systems for Earth remote sensing and other applications]. Tez. dokl. Shestoy mezhdunar. nauch.-tekh. konf. "Aktual'nye problemy sozdaniya kosmicheskikh sistem distantsionnogo zondirovaniya Zemli" [Abs. 6th int. sci.-tech. conf. "Actual problems of aircraft remote sensing systems development"]. Moscow, AO "Korporatsiya "VNIIEM" Publ., 2018, pp. 43-45 (in Russ.).

[5] Platonov V.N. [Control law of gyro stabilization system]. Tr. V nauch.-tekh. konf. molodykh spetsialistov predpriyatiya [Proc. V. sci.-tech. of young specialist]. Kaliningrad, NPO "Energiya" Publ., 1977, pp. 57-69 (in Russ.).

[6] Crenshaw J.W. 2-SPEED, a single-gimbal moment gyro attitude control system. AIAA Paper, 1973, no. 73-895. DOI: 10.2514/6.1973-895

[7] Mikrin E.A., ed. Teoreticheskie osnovy proektirovaniya informatsionno-upravlyayushchikh sistem kosmicheskikh apparatov [Theoretical fundamentals of designing management information system for spacecraft]. Moscow, Nauka Publ., 2006.

[8] Platonov V.N., Sumarokov A.V. Studying the possibility of ensuring the stabilization accuracy characteristics of an advanced spacecraft for remote sensing of the Earth. J. Comput. Syst. Sci. Int., 2018, vol. 57, iss. 4, pp. 655-665.

DOI: $10.1134 /$ S1064230718040123

[9] Aleksandrov V.V., Boltyanskiy V.G., Lemak S.S., et al. Optimal'noe upravlenie dvizheniem [Optimum motion control]. Moscow, Fizmatlit Publ., 2005.

[10] Bryson A.E., Yu-Chi Ho. Applied optimal control: optimization, estimation, and control. Blaisdell Pub. Co., 1969.

[11] Kwakernaak H., Sivan R. Linear optimal control systems. Wiley Interscience, 1972.

[12] Eykhoff P. System identification parameter and state estimation. Wiley, 1974.

[13] Mikrin E.A., Timakov S.N., Bogdanov K.A., et al. Experience and perspectives of the onboard algorithms creation of the spacecraft motion control. Vestnik RFFI, 2017, no. 3 (95), pp. 23-45 (in Russ.).

[14] Sumarokov A.V. On pointing of high resolution camera mounted on the international space station using biaxial rotating platform. Vestn. Mosk. Gos. Tekh. Univ. im. N.E. Baumana, Priborostr. [Herald of the Bauman Moscow State Tech. Univ., Instrum. Eng.], 2016, no. 4, pp. 85-97 (in Russ.).

DOI: $10.18698 / 0236-3933-2016-4-85-97$

[15] Wie B., Bailey D., Heiberg C. Rapid multitarget acquisition and pointing control of agile spacecraft. J. Guid. Control Dyn., 2002, vol. 25, no. 1, pp. 96-104.

DOI: $10.2514 / 2.4854$

Platonov V.N. - Dr. Sc. (Eng.), Head of Department, S.P. Korolev Rocket and Space Corporation Energia (Lenina ul. 4A, Korolev, Moscow Region, 141070 Russian Federation), Professor, MIPT (Institutskiy pereulok 9, Dolgoprudny, Moscow Region, 141701 Russian Federation). 
Application of Single-Gimbal Control Moment Gyros for Attitude Control...

Sumarokov A.V. - Cand. Sc. (Phys.-Math.), Senior Research Scientist, S.P. Korolev Rocket and Space Corporation Energia (Lenina ul. 4A, Korolev, Moscow Region, 141070 Russian Federation), Assist. Professor, MIPT (Institutskiy pereulok 9, Dolgoprudny, Moscow Region, 141701 Russian Federation).

Ryabikov V.S. (1939-2018) - Cand. Sc. (Eng.), worked at AO "NIIEM" (Panvilova ul. 11, Istra, Moscow Region, 143502 Russian Federation).

Makeich S.G. - Head of Sector, Senior Programmer, AO "NIIEM" (Panvilova ul. 11, Istra, Moscow Region, 143502 Russian Federation).

Nekhamkin L.I. - Head of Laboratory, AO "NIIEM" (Panvilova ul. 11, Istra, Moscow Region, 143502 Russian Federation).

Vilenksiy V.V. - Head of Department, JSC "MIC "NPO Mashinostroyenia" (Gagarina ul. 33, Reutov, Moscow Region, 143966 Russian Federation).

Zaytsev S.E. - Area Chief Designer, JSC "MIC "NPO Mashinostroyenia" (Gagarina ul. 33, Reutov, Moscow Region, 143966 Russian Federation).

Korol L.G. - Head of Sector, JSC "MIC "NPO Mashinostroyenia" (Gagarina ul. 33, Reutov, Moscow Region, 143966 Russian Federation).

Rusakov R.O. - Head of Department, JSC "MIC "NPO Mashinostroyenia" (Gagarina ul. 33, Reutov, Moscow Region, 143966 Russian Federation).

\section{Please cite this article in as:}

Platonov V.N., Sumarokov A.V., Ryabikov V.S., et al. Application of Single-Gimbal Control Moment Gyros for Attitude Control of a Radio-Range Earth Remote Sensing Spacecraft. Herald of the Bauman Moscow State Technical University, Series Instrument Engineering, 2019, no. 1, pp. 50-61. DOI: 10.18698/0236-3933-2019-1-50-61 